\title{
Ultrasonography-guided scleral buckle retinopexy and cryotherapy: case report
}

\author{
Retinopexia com "buckle" escleral e crioterapia guiada por ultrassom: relato de caso
}

\author{
Daniel da Rocha Lucena ${ }^{1}$ \\ Jefferson Augusto Santana Ribeiro ${ }^{2}$ \\ Marco Sérgio Pinto Alves Folgosa ${ }^{3}$ \\ Levy da Rocha Lucena ${ }^{4}$ \\ RodrigoJorge $\mathbf{e}^{5}$
}

\begin{tabular}{|l|}
\hline \multicolumn{1}{c|}{ ABSTRACT } \\
\hline If the ocular media are clear, indirect binocular ophthalmoscopy \\
allows retinal detachment and retinal tear identification and treatment \\
under direct visualization. However, if opacities are present preventing \\
direct fundus examination, ultrasonography becomes the most impor- \\
tant tool for evaluating the posterior segment. In addition, ultrasono- \\
graphy can be useful in retinal tear treatment by guiding cryotherapy. \\
In this article we describe a rhegmatogenous retinal detachment treatment \\
technique applied to a patient with corneal opacity. Cryopexy and \\
circumferential and radial buckle positioning were guided by ultraso- \\
nography, resulting in retinal attachment during the 6-month follow- \\
up period.
\end{tabular}

Keywords: Ultrasonography; Retinal detachment/ultrasonography; Scleral buckling; Retinal perforations; Cryotherapy; Corneal opacity; Human; Male; Middle aged; Case reports [Publication types]

\section{INTRODUCTION}

Rhegmatogenous retinal detachment (RD) is a characterized separation between the sensory retina and the retinal pigment epithelium (RPE) caused by a retinal tear $(\mathrm{RT})^{(1-2)}$.

In patients with clear ocular media, indirect binocular ophthalmoscopy (IBO) allows the identification of RD and RTs and their treatment under direct visualization. However, for patients with opaque ocular media due to cataract, vitreous hemorrhage or corneal leukoma that prevent ophthalmoscopic examination, ultrasonography becomes the most important tool for evaluation of the posterior segment of the eye $\mathrm{e}^{(3)}$. In addition, ultrasound can also be of help for the treatment of RTs with guiding cryotherapy $^{(3-5)}$.

The treatment of early rhegmatogenous RD is reported in which ultrasound-guided cryopexy and evaluation of the positioning of circumferential and radial buckles were performed in a patient with corneal leukoma.

\section{CASE REPORT}

A 56-year-old mulatto man followed up at the Corneal Sector of the School of Medicine of Ribeirão Preto Clinics Hospital, University of São Paulo, was referred to the Ocular Ultranosography Sector for evaluation of the posterior segment of the right eye (OD) as part of the preoperative workup for corneal transplantation in May 2007. The patient had cicatricial trachoma in both eyes (OU), visual acuity of light perception and projection in OD 
and no light perception in OS, and applanation tonometry of 14/10 mmHg. Biomicroscopy showed an important corneal leukoma in OU which prevented the execution of IBO. Ultrasonographic evaluation consisted initially of crosswise screening sections with a $10 \mathrm{MHz}$ probe in B-mode. In OD, after the RT was detected at the upper temporal periphery (10:30 hours), crosswise and lengthwise sections were performed to determine the three-dimensional format of the lesion and its relation to other ocular structures. Echography revealed a RT in OD with a flap characterized by a well-defined linear structure of high reflectivity with its anterior portion adhered to the retina and the posterior portion elevated, adhered to the posterior hyaloid membrane (PHM) and directed towards the posterior pole of the ocular globe. It was possible to determine the traction exerted by the PHM on the RT flap, as well as the halo of shallow retinal detachment in OD (Figure 1A). Echographic examination of OS revealed total closed funnel RD and retinal cysts. In view of the ultrasound findings in OD and of the impossibility of eye fundus visualization, we opted for ultrasoundguided surgical treatment with a $10 \mathrm{MHz}$ probe in B-mode, which consisted of cryopexy, circumferential and radial scleral buckles, and pneumatic retinopexy. After the first postoperative week, the retina was attached and showed no further tears, remaining so until the last echographic examination at 6 months of follow-up (Figure 1B). The patient is currently waiting for corneal transplant in this eye.

Under peribulbar anesthesia, cryotherapy, scleral buckle and pneumatic retinopexy were performed on OD in the same surgical act. For the ultrasound-guided procedures (cryotherapy, and positioning of buckle) we used an operative field without a blepharostat, the ultrasound probe and cable wrapped in a sterile plastic field (Protect-Cam ${ }^{\circledR}$, Minas Import LTDA.), a non-sterile conductor gel (Sonic-Plus ${ }^{\circledR}$, Hal Indústria e Comércio) between the tip of the probe and the plastic field, and sterile 4\% methylcellulose (Ophthalmos Indústria Farmacêutica LTDA.) for the contact between the sterile field and the operative field/lower eyelid of the patient (Figure 2A).

Ultrasound-guided cryopexy was first performed. Indentation of the anterior, posterior, medial and lateral tear margins was performed with the cryoprobe using crosswise and lengthwise sections. Freezing was observed in real time by ultrasound by the progressive increase of ocular wall thickness and reflectivity and by the presence of the "ice ball" that remained for a few seconds after cryotherapy (Figure 2B). The second surgical step consisted of the placement of a circumferential scleral buckle of solid silicone (silicone strip style 42). After this step, ultrasonography showed that the posterior tear margin was positioned posteriorly to the indentation (Figure 2C); thus the placement of a radial buckle of solid silicone (silicone tire style 287) was indicated in order to indent the entire tear. During this step, ultrasound was again used to guide the correct positioning of the radial segment, after which there was total indentation of the tear and relief of vitreous traction on the retinal flap (Figure 2D). Finally, paracentesis of the anterior chamber and intravitreous injection of $0.3 \mathrm{ml} 100 \%$ perfluoropropane $\left(\mathrm{C}_{3} \mathrm{~F}_{8}\right)$ were performed. Postoperatively, the gas bubble was placed over the tear by adequate patient head positioning. The patient had a favorable course, with separation between the PHM and the retinal flap and reattachment of the retina starting one week after surgery.
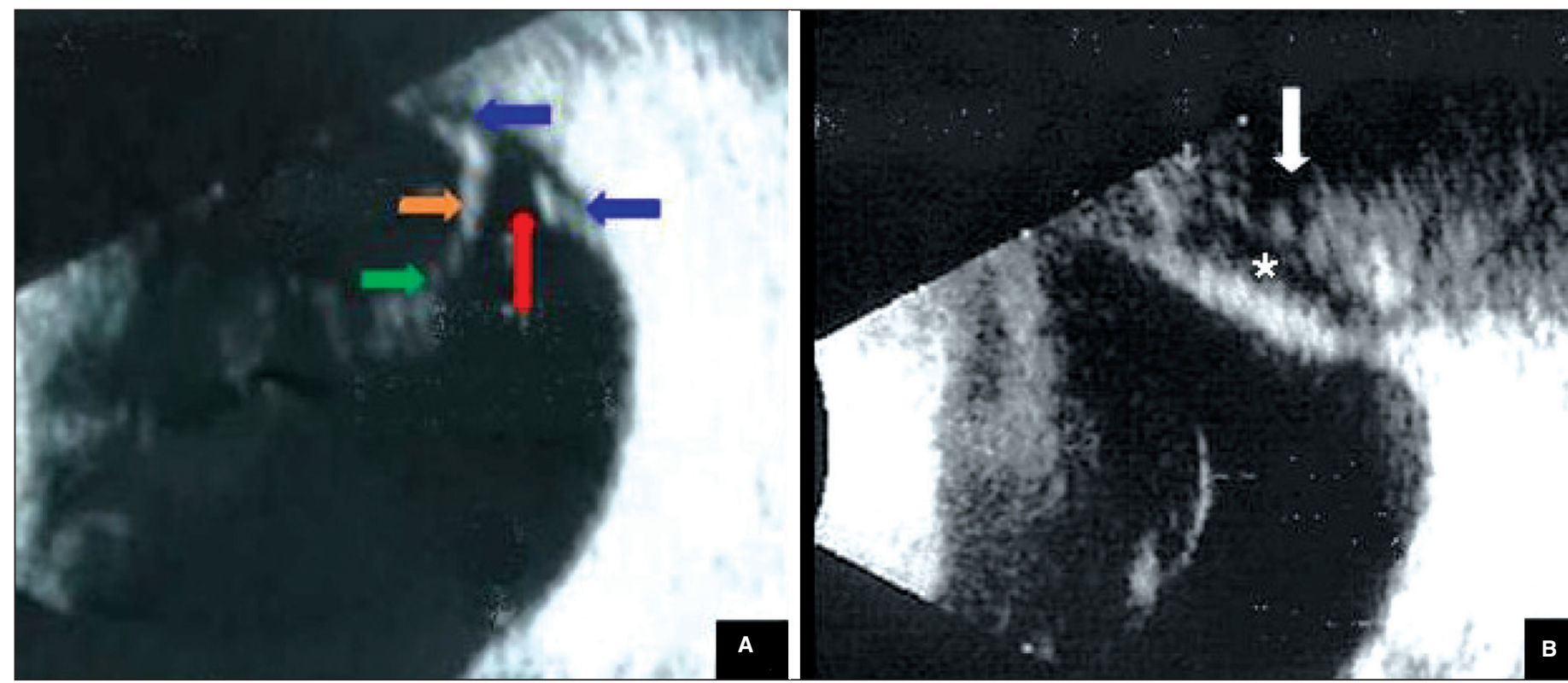

Figure 1 - B-Mode ultrasonography with a $10 \mathrm{MHz}$ probe showing the preoperative (A) and postoperative (B) aspect of upper temporal periphery in lengthwise sections of the right eye. A) Retinal tear (red arrow), halo of retinal detachment (blue arrows), retinal flap (orange arrow) and posterior hyaloid membrane adhered to the retinal flap margin (green arrow); B) After 6 months - attached retina, total posterior vitreous detachment and radial (asterisk) and circumferential (white arrow) scleral buckle (style 42) indentation. 

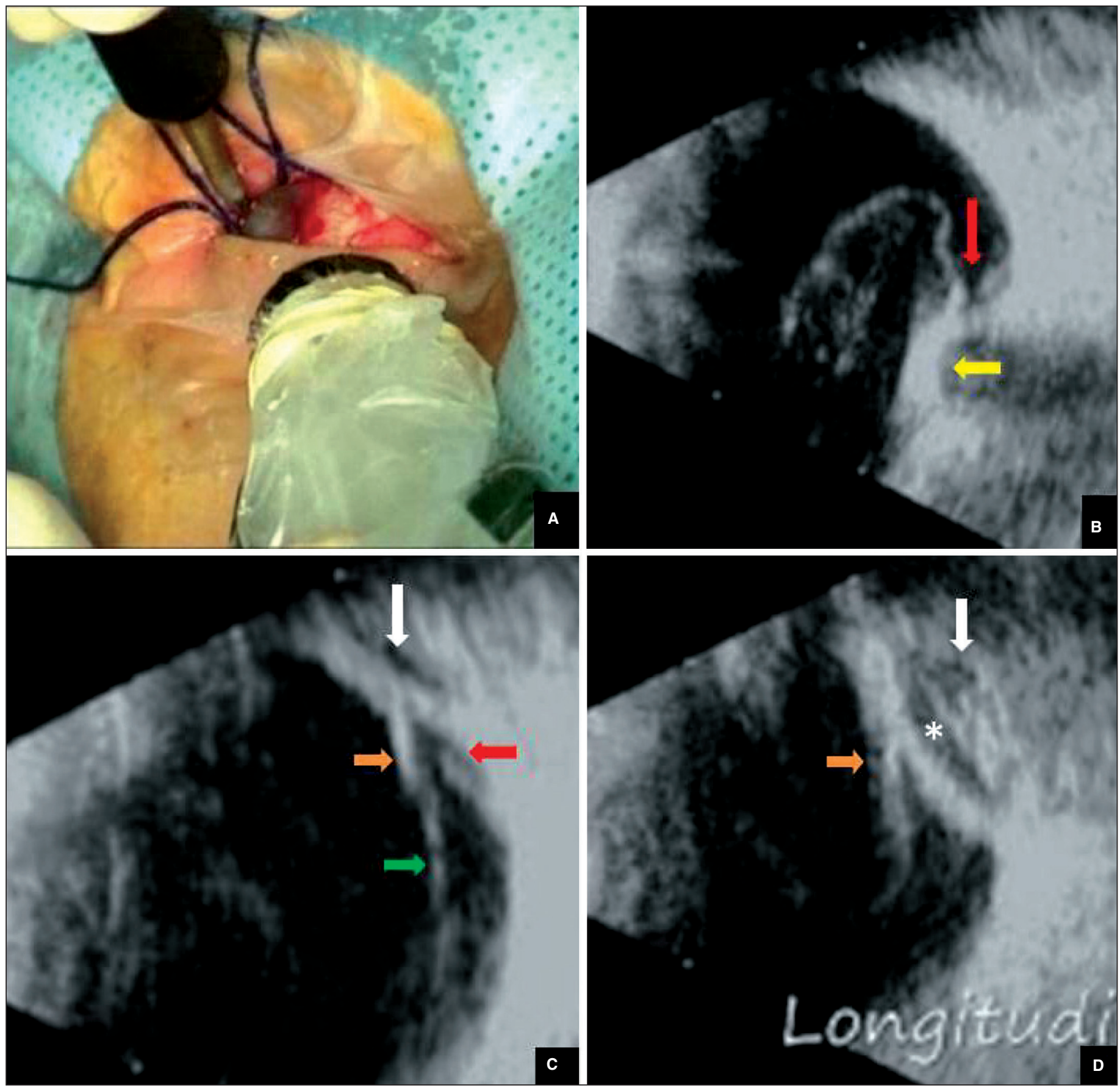

Figure 2 - Ultrasonography-guided retinopexy. A) Ultrasonography $10 \mathrm{MHz}$ probe lower nasal and cryoprobe upper temporal in the right eye with sterile operative field; B) Upper temporal crosswise section echography showing "ice ball" formation during cryotherapy (yellow arrow) of lateral tear margin; C) Inadequately indented retinal tear (red arrow) with circumferential scleral buckle (style 42) (white arrow). Notice retinal flap (orange arrow) adhered to the posterior hyaloid membrane (green arrow); D) Total indentation of retinal tear after radial buckle (asterisk) placement guided by ultrasonography.

\section{DISCUSSION}

Echographic ocular examination has a well-established role in the evaluation of vitreoretinal structures, showing high sensitivity and specificity in the diagnosis of $\mathrm{RT}^{(3,6)}$. In some cases, however, RTs may be confused with areas of retinal neovascularization ${ }^{(3)}$, and retinal holes may not be detected by ultrasound ${ }^{(4)}$. In the present patient, an important corneal leukoma prevented visibility of the eye fundus, but the diagnosis of the RT and the traction exerted by the PHM on its flap, as well as the halo of shallow RD, was possible by ultrasound. Possible differential diagnoses 
include PHM detachment and thickening and retinal neovascularization.

Surgical treatment of rhegmatogenous RD basically involves three techniques: pneumatic retinopexy, scleral introflexion, and vitrectomy. These techniques can be used separately or, in certain cases, they can be combined ${ }^{(1,7)}$. Permanent chorioretinal adhesion should be created in the margins of the tear and this can be obtained with laser, diathermy or cryopexy ${ }^{(1-2)}$. In the present case, scleral buckle and pneumatic retinopexy were performed in addition to cryopexy in view of the high rate of retinal reattachment which is obtained by this technique with a single surgery ${ }^{(8)}$, since postoperative follow-up of the patient by ultrasound with intraocular gas is compromised and the surgical success of a single operation is lower for pneumatic retinopexy compared to scleral buckle ${ }^{(6,9)}$. There was no need to drain the subretinal fluid because the RD was shallow.

Ocular ultrasound has also been used as an aid in the treatment of retinal injuries, tears in particular ${ }^{(5)}$. Ultrasound-guided cryopexy is an effective treatment for single RTs associated with vitreous hemorrhage or advanced cataract ${ }^{(4)}$. In the present study, ultrasound proved to be useful not only for the execution of cryopexy, as described in the literature, but also for the indication and monitoring of the positioning of the radial buckle intra-operatively. Another important fact in this case was that posterior vitrectomy, the only possibility of retinal treatment under direct visualization, would only be possible if combined with the use of a keratoprosthesis, a more aggressive, longer-lasting and more expensive procedure; moreover there was difficulty for corneal transplantation, with shortage of corneas, a known problem in Brazil.

One of the difficulties faced during ultrasound-guided cryotherapy is the control of the duration of freezing and of the extent of treatment. Thus, when ophthalmoscopic examination of the lesion becomes possible, patients treated with the aid of ultrasound may require complementary laser treatment ${ }^{(4)}$. In the present study, the increased reflectivity and thickening of the ocular wall was used to determine the time of cryotherapy application and the presence of an "ice ball" was detected immediately after the removal of the cryotherapy probe, confirming the efficacy of the procedure. Ophthalmoscopic control was not possible because the patient had not yet been submitted to corneal transplant.

Thus, ultrasound proved to be an adequate method not only for the execution of cryopexy, but also for the evaluation of the positioning of the circumferential scleral buckle in relation to the tear and for the indication of the radial scleral buckle when the circumferential one did not provide full rupture indentation. This is very important because it increases the rate of success in a single procedure combined with pneumatic retinopexy.

\section{RESUMO}

Quando os meios oculares são transparentes, oftalmoscopia binocular indireta permite a identificação de descolamento de retina e roturas, bem como seu tratamento sob visibilização direta. Porém, em olhos que apresentam opacidades de meios impedindo o exame oftalmoscópico, a ultrassonografia constitui o exame mais importante do segmento posterior do olho. Além disso, o tratamento de roturas retinianas também pode ser auxiliado pelo uso desse equipamento, orientando a crioterapia. Neste trabalho será apresentada técnica de tratamento de descolamento de retina regmatogênico, no qual a criopexia e o posicionamento dos "buckles" episclerais circunferencial e radial foram guiados pelo ultrassom em paciente com leucoma corneano. O tratamento resultou em aplicação retiniana durante o seguimento em seis meses.

Descritores: Ultrassonografia; Descolamento retiniano/ultrassonografia; Recurvamento da esclera; Perfurações retinianas; Crioterapia; Opacidade da córnea; Humano; Masculino; Meia-idade; Relatos de casos [Tipo de publicação]

\section{REFERENCES}

1. Michels RG, Wilkinson CP, Rice TA. Retinal detachment. St. Louis: CV Mosby; 1990.

2. Machemer R. The importance of fluid absorption, traction, intraocular currents and chorioretinal scars in the therapy of rhegmatogenous retinal detachments.XLI Edward Jackson Memorial lecture. Am J Ophthalmol. 1984;98(6): 681-93.

3. DiBernardo C, Blodi B, Byrne SF. Echographic evaluation of retinal tears in patients with spontaneous vitreous hemorrhage. Arch Ophthalmol. 1992;110(4) 511-4.

4. Schenek M, Rosenthal G, Klemperer I, Yagev R, Lifshitz T. Ultrasound guided cryotherapy for retinal tears in patients with opaque ocular media. $\mathrm{Br}$ J Ophthalmol. 1999;83(5):628-9.

5. Kelley LM, Walker JP, Wing GL, Raskauskas PA, Schepens CL. Ultrasoundguided cryotherapy for retinal tears in patients with vitreous hemorrhage. Ophthalmic Surg Lasers. 1997;28(7):565-9. Comment in: Ophthalmic Surg Lasers. 1998;29(5):436-7.

6. Lucena DR, Lucena LR. Ecografia em retina. In: Oréfice F, Siqueira RC, Rocha IML organizadores. Guia para o cirurgião de segmento anterior-retina e vítreo. Rio de Janeiro: Cultura Médica; 2006. p.41-4.

7. Glaser BM, Michels RG. Surgical retina. In: Ryan SJ. Retina. St. Louis: CV Mosby; 1989. p.105-9.

8. Gilbert C, McLeod D. D-ACE surgical sequence for selected bullous retinal detachments. Br J Ophthalmol. 1985;69(10):733-6.

9. Han DP, Mohsin NC, Guse CE, Hartz A, Tarkanian CN. Comparison of pneumatic retinopexy and scleral buckling in the management of primary rhegmatogenous retinal detachment. Southern Wisconsin Pneumatic Retinopexy Study Group. Am J Ophthalmol. 1998;126(5):658-68. Comment in: Am J Ophthalmol. 1999;127(6):741-3. 